\title{
IDENTIFICAÇÃO DE PERDAS POR IMPROVISAÇÃO EM CANTEIROS DE OBRAS
}

\author{
Investigation of wastes due improvisation in construction sites
}

\author{
Tatiana Gondim do Amaral ${ }^{1}$, Camila Mariana Brandão ${ }^{2}$, Karinny Vieira Elias ${ }^{3}$, Pedro Boaratti Braga ${ }^{4}$
}

Recebido em 22 de fevereiro de 2019; aceito em 06 de junho de 2019; disponível on-line em 28 de junho de 2019.

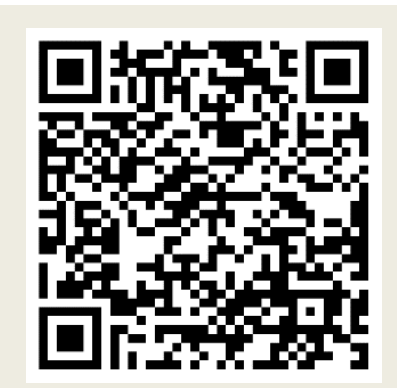

PALAVRAS CHAVE:

Perdas;

Making-do;

Retrabalho;

Improvisação;

Gestão;

KEYWORDS:

Losses;

Making-do;

Rework;

Improvisation;

Management.

\begin{abstract}
RESUMO: O making-do se destaca porque representa um potencial para gerar outras perdas, como redução de segurança, problemas de qualidade, produtividade e retrabalho. O principal objetivo da pesquisa é analisar e investigar as perdas por making-do, relacionadas à de gestão da produção de três empresas de Goiânia, com a finalidade de identificar as categorias de perda e seus possíveis impactos. A pesquisa é classificada como quantitativa e qualitativa, também como aplicada e exploratória. Com base nisso, foram analisados dados durante as visitas técnicas em cada obra, dentre as quais se destaca a observação direta não participante, a aplicação de questionário e a análise documental. Em acréscimo foram realizados registros fotográficos das atividades produtivas com ocorrência de perdas, além da análise da organização do canteiro de obras dos empreendimentos em estudo. Os resultados deste estudo indicaram que a maioria das improvisações está relacionada ao planejamento de curto prazo, logística e projetos. No entanto, os impactos mais importantes desses tipos de perdas são a necessidade de retrabalho e perda de material. Como resultados detaca-se a importância do estudo das perdas relacionadas ao making-do, uma vez que gera outros tipos de perdas, e vai além do desperdício de materiais, evidenciando-se questões relacionadas à saúde e segurança da mão de obra e impactos no processo de produção como um todo.
\end{abstract}

ABSTRACT: The making-do stands out because it represents a potential to generate other losses, such as security reduction, quality problems, productivity and rework. The main objective of the research is to analyze and investigate the losses by making-do, related to the management of the production of three companies of Goiania, for the purpose of identifying the categories of loss and their possible impacts. The research is classified as quantitative and qualitative, also as applied and exploratory. Based on this, data were analyzed during the technical visits in each work, among which stands out the non-participant direct observation, the application of questionnaire and the documentary analysis. In addition, photographic records of the productive activities with the occurrence of losses were carried out, in addition to the analysis of the organization of the construction site of the projects in study. The results of this study indicated that most improvisations are related to short-term planning, logistics and projects. However, the most important impacts of these types of losses are the need for rework and loss of material. As a result, the importance of the study of the losses related to the making-do stands out, since it generates other types of losses, and goes beyond the waste of materials, evidencing issues related to the health and safety of the workforce and impacts in the process of Production as a whole.

\footnotetext{
* Contato com os autores:

${ }^{1}$ e-mail: tatiana_amaral@hotmail.com (T. G. Amaral)

Enga. Civil, Doutora, Professora da Escola de Engenharia Civil e Ambiental da Universidade Federal de Goiás - UFG.

2e-mail: c.mariana.b@gmail.com (C. M. Brandão)

Graduanda em Engenharia Civil na Escola de Engenharia Civil e Ambiental da Universidade Federal de Goiás - UFG.

${ }^{3}$ e-mail: karinnyelias22@gmail.com (K. V. Elias)

Graduanda em Engenharia Civil na Escola de Engenharia Civil e Ambiental da Universidade Federal de Goiás - UFG.

${ }^{4}$ e-mail: pedrobraga.engcivil@gmail.com (P. B. Braga)

Graduando em Engenharia Civil na Escola de Engenharia Civil e Ambiental da Universidade Federal de Goiás - UFG.
} 


\section{INTRODUÇÃO}

Após o crescimento de $13,1 \%$ do PIB da indústria da construção no ano de 2010 em relação a 2009, a construção civil apresentou uma retração acentuada entre 2010 e 2017 com um ápice negativo no primeiro semestre de 2017 de 6,6\% (SINICON/LCA/IBGE, 2017).

Dos componentes do PIB brasileiro, foi o que apresentou maior queda em 2017. Enquanto o PIB nacional reduziu 5,5\%, a queda da participação da construção civil nesse indicador, para o mesmo período, foi de $14,3 \%$. Quase 1 milhão dos 2,7 milhões de empregos formais que deixaram de existir no país foram na construção civil (SINICON/LCA/IBGE, 2017).

No estado de Goiás, em dezembro de 2017, a retração de empregos na construção civil foi de 4,6\% em relação ao mês anterior, fechando no valor de 62.321 postos de trabalhos preenchidos. No mesmo levantamento, é apresentada uma ligeira melhora nos dados referentes a janeiro de 2018 com valor positivo de $2,7 \%$ em relação ao mês anterior, todavia seguido por valor de $0,3 \% \mathrm{em}$ fevereiro de 2018. Diante dos dados expostos, a previsão de crescimento ainda é incerta (SINICON/IBGE, 2017).

Neste cenário, sobressaem as empresas com melhores práticas construtivas, concomitantemente com menores perdas operacionais. Segundo Koskela (1992), a diminuição de desperdícios melhora os índices de produtividade, aumenta a qualidade da construção, flexibiliza os prazos de execução da obra, reduz custos e possibilita o aumento da satisfação do cliente, fatores indispensáveis para a competitividade das empresas.

Além das sete perdas identificadas por Ohno (1997), Koskela (2004) propôs uma nova categoria de perda denominada de making-do. No Brasil, a perda por making-do vem sendo levantada em diversos autores, tais como Sommer (2010), Leão (2014) e Santos e Santos (2017).

Particularmente em Goiânia, o levantamento de perda por making-do se integra a um grupo de pesquisa, no qual estão sendo feitos levantamentos em empresas goianas para identificar a presença de perdas por making-do e seus impactos, destacando-se os trabalhos de Braga (2018), Brandão e Elias (2018) e Dinoah, Martins e Ribeiro (2018).

Esse trabalho visa contribuir para o levantamento de dados referentes às perdas por making-do e as relações entre as falhas na gestão da produção, com a finalidade de identificar as categorias de perdas por improvisação e possíveis impactos gerados por elas.

\section{REVISÃO BIBLIOGRÁFICA}

Além das perdas classificadas por Formoso (1997) foi identificado um novo tipo de perda denominado making-do, que se destaca por representar uma potencialidade de geração de outras perdas como redução da segurança, problemas de qualidade, work in progress $\mathrm{e}$ retrabalho (SOMMER, 2010; FORMOSO et al., 2011; FIREMAN et al., 2013).

Koskela (2004) define making-do como a perda que ocorre quando uma tarefa inicia sem todas as suas entradas, ou quando ela tem sua execução continuada, mesmo com a cessão de uma ou mais entradas. Observa ainda que o modelo de gestão e planejamento da construção está todo voltado para a tarefa iniciada, ao passo que as discrepâncias entre o que foi planejado e o mundo real não são levados em conta, o que resulta em situações nas quais o making-do aparece como única solução para que o trabalho não seja interrompido. Assim, o planejamento da obra estabelece os pacotes de trabalho e não havendo condições de trabalho são identificadas as perdas por making-do.

A partir dos estudos de Koskela (2000), Sommer (2010) e Fireman (2012), foram identificadas algumas categorias de perdas por making-do, pré-requisitos necessários e possíveis impactos gerados por elas. Sommer (2010) apresentou sete categorias de 
perdas e Fireman (2012) acrescentou a categoria sequenciamento, totalizando assim, oito categorias de perda por making-do.

A seguir, seguem as definições das categorias de perdas criadas por Sommer (2010) e Fireman (2012):

1) Acesso/mobilidade: Relativo ao espaço, meio ou forma de posicionamento de quem executa as tarefas;

2) Ajustes de componentes: relacionado à existência de algum ajuste inesperado que seja necessário para uso de componentes ou elementos de construção não adequados à realização das tarefas;

3) Área de trabalho: Refere-se à bancada de trabalho ou área de apoio durante as atividades realizadas;

4) Armazenamento: Organização de materiais ou componentes em locais não preparados para o seu recebimento;

5) Equipamentos/ferramentas: criados ou adaptados para uso durante as atividades;

6) Instalações provisórias: criados ou adaptados para uso durante as atividades;

7) Proteção: Forma de uso dos sistemas de proteção;

8) Sequenciamento: Alteração pela equipe na sequência de produção.

As perdas são causadas pela falta ou má execução de um conjunto de pré-condições ou pré-requisitos necessários para início de uma atividade. Koskela (2000) identificou sete itens de pré-requisitos e Sommer (2010) apresentou um estudo agrupando alguns itens e criando outros, em que resultou em oito itens, sendo eles:
1) Informação: não estão disponíveis informações adequadas referentes a planos, estudos, ou trabalho;

2) Materiais e componentes: atividade com qualidade, quantidade e dentro das especificações de projeto e normas;

3) Mão de obra: não estão disponíveis os recursos humanos necessários, em número ou qualificação;

4) Equipamentos: não estão disponíveis, não funcionam ou não são adequados às tarefas;

5) Espaço: não há acesso à área de trabalho, circulação ou relativo à estocagem de materiais;

6) Serviços interligados: atividades com alta interdependência comprometem a execução das tarefas subsequentes;

7) Condições externas: vento, chuva ou temperaturas extremas;

8) Instalações: não atendem as necessidades para execução dos pacotes de trabalho, incluem-se: instalações elétricas e hidráulicas provisórias, instalações para segurança do canteiro, isolamento das áreas de estoque, andaimes e fechamentos.

Autores como Koskela (2004) e Sommer (2010) estudaram alguns impactos causados pelas perdas já apresentadas, em conjunto com estes, Fireman (2012) acrescentou um impacto denominado falta de terminalidade. Pode-se observar então, que o making-do é de extrema importância, pois gera outros tipos de perdas. As classificações apresentadas estão descritas na Figura 2. 


\begin{tabular}{|c|}
\hline \multicolumn{1}{|c|}{ Pré-condições / Pré- } \\
requisitos \\
•Informação \\
•Materiais e Componentes \\
•Mão-de-obra \\
•Equipamentos/Ferramentas \\
•Espaço \\
•Serviços interdependentes \\
$\bullet$ Condições externas \\
•Instalações
\end{tabular}

\begin{tabular}{|l|}
\hline \multicolumn{1}{|c|}{ Categorias } \\
•Acesso/mobilidade \\
-Ajuste de componentes \\
-Arrea de trabalho \\
- Equipamentos/Ferramentas \\
•Instalações provisórias \\
• Proteção
\end{tabular}

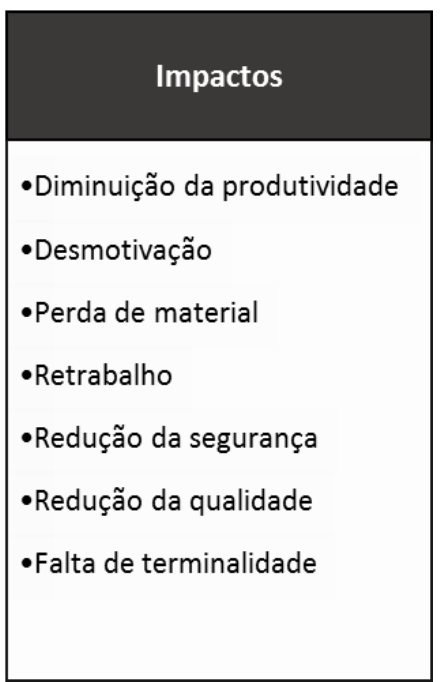

FIGURA 2:Classificação de perdas por making-do.

FONTE: Koskela (2004), Sommer (2010), Fireman (2012) adaptado.

Sommer (2010) mostra em sua pesquisa o percentual de improvisações por categoria proposta, indicando que o maior número de registros (36\%) foram relacionados à acesso/mobilidade, seguida por proteção (Figura 3). Além disso, faz uma análise dos casos que ocorreram de forma continuada e repetida, $32 \%$ dos registros, destacando que as categorias acesso/mobilidade e proteção apresentam maior incidência (Figura 4).

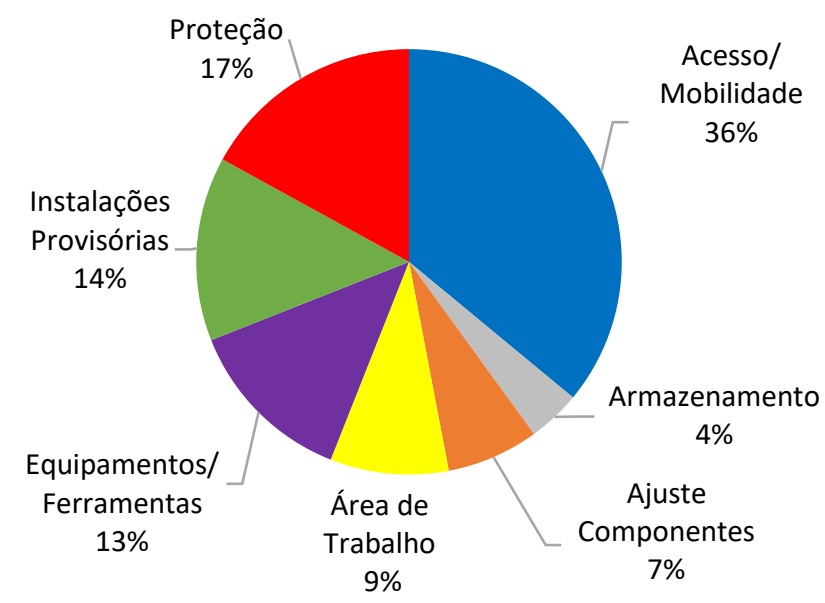

FIGURA 3: Percentual de improvisação observado por categoria. FONTE: Sommer (2010).

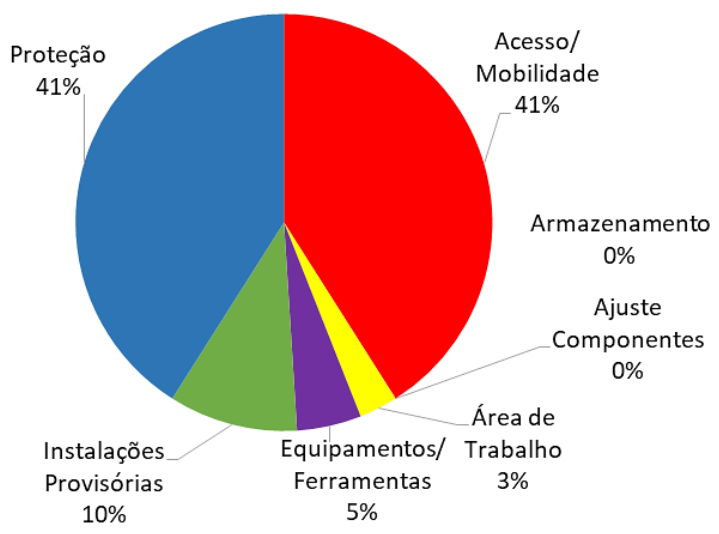

FIGURA 4: Percentual de casos recorrentes de perda por improvisação.

FONTE: Sommer (2010). 


\section{METODOLOGIA}

Com relação à abordagem, a pesquisa se classifica como quantitativa e qualitativa, por analisar os resultados numéricos provenientes às perdas identificadas em empresas construtoras da cidade de Goiânia e por apresentar significados, sentidos, resultados e interpretações teóricas sobre as perdas identificadas.

Quanto à natureza, a pesquisa é aplicada, pois tem como um dos objetivos principais a produção de conhecimento a ser utilizado na construção civil.

Com relação aos objetivos e procedimentos, a pesquisa é classificada como exploratória.

\subsection{DELINEAMENTO}

A pesquisa apresenta o delineamento representado pela Figura 5 .

\subsection{CARACTERIZAÇÃO DAS EMPRESAS PARTICIPANTES DA PESQUISA}

Os dados foram levantados em três empresas construtoras da cidade de Goiânia entre os meses de fevereiro a junho de 2018 , levando-se em consideração dados apresentados pelas empresas desde o início da obra.

A partir da definição das empresas participantes foi realizada uma caracterização apresentada no Quadro 1.

$O$ estudo foi realizado em um empreendimento de cada empresa caracterizadas pelo Quadro 2.

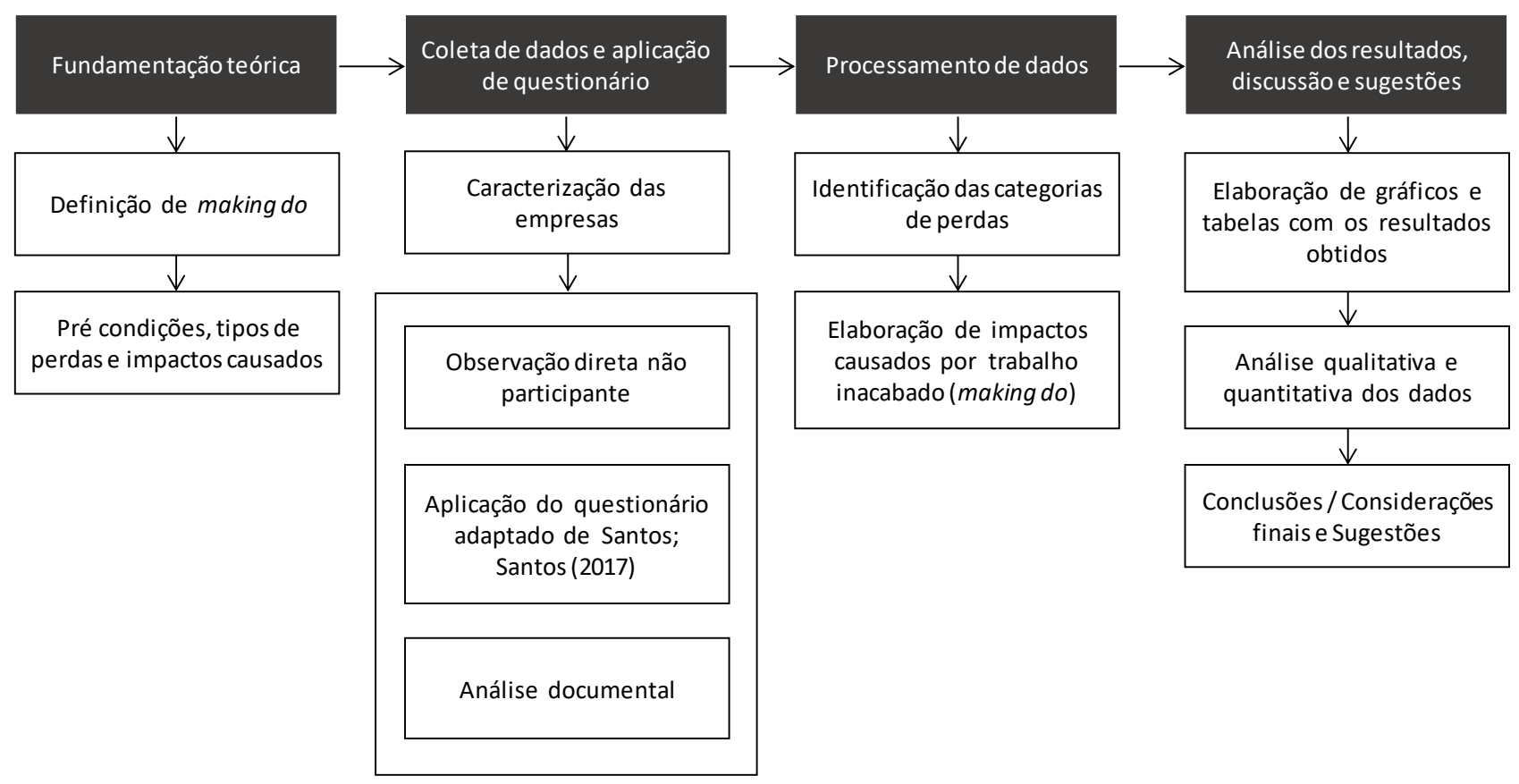

FIGURA 5: Delineamento da pesquisa.

FONTE: Autoria própria. 


\begin{tabular}{|c|c|c|c|c|c|}
\hline Empresa & Certificações & $\begin{array}{l}\text { Tempo de } \\
\text { atuação no } \\
\text { mercado }\end{array}$ & $\begin{array}{c}\text { Obras em andamento no } \\
\text { primeiro semestre de } \\
2018\end{array}$ & \begin{tabular}{|c|}
$\mathrm{m}^{2}$ em \\
execução em \\
2018
\end{tabular} & $\begin{array}{l}\text { Porte da } \\
\text { empresa }\end{array}$ \\
\hline \multirow{4}{*}{ A } & $\begin{array}{l}\text { ABNT NBR ISO 14001:2004 - } \\
\text { Sistema de Gestão Ambiental }\end{array}$ & \multirow{4}{*}{21 anos } & $\begin{array}{l}01 \text { empreendimento } \\
\text { residencial de médio } \\
\text { padrão }\end{array}$ & $47.789,71$ & \multirow{4}{*}{ Grande porte } \\
\hline & ABNT NBR ISO 9001:2008 & & 01 faculdade & $11.063,00$ & \\
\hline & $\begin{array}{l}\text { OHSAS 18001:2007-Sistema de } \\
\text { Gestão da Saúde e Segurança do } \\
\text { Trabalho }\end{array}$ & & \multirow{2}{*}{$\begin{array}{l}03 \text { EHIS (um em Goiânia e } \\
\text { dois no Rio de Janeiro) }\end{array}$} & $\begin{array}{c}12.493,00 \mathrm{GO} \\
12.595,01 \mathrm{RJ}\end{array}$ & \\
\hline & $\begin{array}{l}\text { PBQP-H NÍVEL A - Sistema de } \\
\text { Gestão da Qualidade }\end{array}$ & & & $26.001,22 \mathrm{RJ}$ & \\
\hline \multirow{4}{*}{ B } & ABNT NBR ISO 9001:2008 & \multirow{4}{*}{19 anos } & $\begin{array}{l}01 \text { empreendimento } \\
\text { residencial de médio }\end{array}$ & $20.853,13$ & \multirow{4}{*}{ Grande porte } \\
\hline & & & O2 empreendimentos & $23.219,83$ & \\
\hline & \multirow{2}{*}{$\begin{array}{l}\text { PBQP-H NÍVEL A - Sistema de } \\
\text { Gestão da Qualidade }\end{array}$} & & residenciais de alto & $24.796,84$ & \\
\hline & & & 01 hotel + residencial & $19.572,45$ & \\
\hline & ABNT NBR ISO 9001:2015 & \multirow[b]{2}{*}{32 anos } & \multirow{2}{*}{$\begin{array}{l}02 \text { empreendimentos } \\
\text { residenciais de médio } \\
\text { padrão }\end{array}$} & \multirow{2}{*}{$\begin{array}{l}27.169,88 \\
29.279,84\end{array}$} & \multirow[b]{2}{*}{ Grande porte } \\
\hline $\mathrm{C}$ & $\begin{array}{l}\text { PBQP-H NÍVEL A - Sistema de } \\
\text { Gestão da Qualidade }\end{array}$ & & & & \\
\hline
\end{tabular}

FONTE: Autoria própria.

\begin{tabular}{|c|c|c|c|c|c|c|}
\hline Obra & Pavimentos & $\begin{array}{l}\text { Número } \\
\text { de torres }\end{array}$ & \begin{tabular}{|c|}
$\begin{array}{c}\text { Fases em execução no } \\
\text { período em estudo }\end{array}$ \\
\end{tabular} & \begin{tabular}{|c|}
$\mathrm{m}^{2}$ de \\
construção
\end{tabular} & Mão de obra & Data de entrega prevista \\
\hline \multirow{4}{*}{ A } & 03 subsolos & \multirow{4}{*}{2} & Alvenaria & \multirow{4}{*}{$47.789,71$} & \multirow{4}{*}{$\begin{array}{c}\text { Maioria } \\
\text { Tercerizada }\end{array}$} & \multirow{2}{*}{ Torre A - Outubro 2018} \\
\hline & 01 térreo & & Instalações & & & \\
\hline & 27 pavimentos tipo & & Esquadrias & & & \multirow{2}{*}{ Torre B - Abril/2018 } \\
\hline & 03 Penthouses / 01 cobertura & & Acabamentos & & & \\
\hline \multirow{5}{*}{ B } & 03 subsolos & \multirow{5}{*}{1} & \begin{tabular}{|l|} 
Estrutura \\
\end{tabular} & \multirow{5}{*}{$20.853,13$} & \multirow{5}{*}{$\begin{array}{c}\text { Maioria } \\
\text { Tercerizada }\end{array}$} & \multirow{5}{*}{ Outubro/2018 } \\
\hline & 01 térreo & & Alvenaria & & & \\
\hline & 01 pavimento de garagem/lazer & & Instalações & & & \\
\hline & 31 pavimentos tipo & & Esquadrias & & & \\
\hline & 01 ático & & Acabamentos & & & \\
\hline \multirow{5}{*}{ C } & 01 subsolo & \multirow{5}{*}{1} & Estrutura & \multirow{5}{*}{$27.169,88$} & \multirow{5}{*}{$\begin{array}{c}\text { Tercerizada e } \\
\text { Própria }\end{array}$} & \multirow{5}{*}{ Outubro/2019 } \\
\hline & 01 térreo & & Alvenaria & & & \\
\hline & 03 pavimentos de garagem & & Instalações & & & \\
\hline & 01 pavimento de lazer & & Esquadrias & & & \\
\hline & 28 pavimentos tipo & & Acabamentos & & & \\
\hline
\end{tabular}

FONTE: Autoria própria.

\subsection{LEVANTAMENTO E ANÁLISE DE DADOS}

Foram analisados dados durante as visitas técnicas em cada obra, dentre as quais se destaca a observação direta não participante, a aplicação de questionário e a análise documental.

Os dados foram coletados conforme a planilha de exemplos apresentada no Apêndice A.

\subsubsection{Observações diretas não participantes com registros fotográficos}

Foram realizadas visitas nos empreendimentos sem intervenção nas atividades em canteiros, a fim de identificar perdas por improvisação.

As ocorrências também foram coletadas 
por meio de entrevistas não estruturadas com engenheiros, estagiários, mestre de obras e encarregados, sendo fornecidos dados desde a etapa de fundação.

Em acréscimo foram realizados registros fotográficos das atividades produtivas com ocorrência de perdas, além da análise da organização do canteiro de obras dos empreendimentos em estudo.

\subsubsection{Aplicação de questionário de planejamento e controle de produção}

Aplicou-se o questionário apresentado no Apêndice B, adaptado do estudo de Santos e Santos (2017), realizado com os engenheiros responsáveis, mestre de obras e encarregados de diversos serviços, para entendimento do planejamento de curto prazo relacionado ao empreendimento em estudo.

\subsubsection{Análise documental}

Foram solicitados às empresas documentos necessários ao estudo relacionado à gestão de produção das mesmas, tais como, projeto executivo e de canteiro de obras, cronograma da obra, fichas de verificação de serviços, além de documentos de planejamento de curto prazo. Deixando a critério de cada empresa a disponibilização dos documentos solicitados.

\subsubsection{Processamento de dados}

Os dados foram analisados por meio de uma planilha criada na plataforma Microsoft Excel, conforme Apêndice A, em que foram classificados de acordo com a categoria, o pré-requisito e os impactos gerados para toda perda identificada. Assim, observou-se que além dos impactos já apresentados por Koskela (2004), Sommer (2010) e Fireman (2012), foram sugeridos pelas autoras mais dois impactos, custo e cronograma.

Foi aplicada uma matriz, proposta inicialmente por Fireman (2012) para análise de riscos das perdas por making-do avaliando a severidade e probabilidade de ocorrência de cada caso (Figura 6).

A partir de uma análise subjetiva das ocorrências foi possível classificá-las como maior prioridade (vermelho), prioridade intermediária (amarelo) e menor prioridade (verde), com o intuito de propor discussões específicas para os casos mais relevantes e indicar as prioridades a serem analisadas pelas empresas. A análise foi realizada comparando-se a probabilidade de ocorrência do caso e a severidade dos impactos causados por ele.

\section{ANÁLISE DE DADOS E DISCUSSÃO DE RESULTADOS}

Após a análise dos dados obtidos nas três obras, foi possível identificar que as categorias de maior ocorrência incidiram na seguinte ordem: sequenciamento, ajuste de componentes e área de trabalho (Figura 7).

\begin{tabular}{|l|l|l|l|l|l|}
\hline \multirow{2}{*}{\multicolumn{1}{c|}{ PROBABILIDADE }} & \multicolumn{4}{c|}{ SEVERIDADE } \\
\cline { 2 - 6 } & Muito Alta - I & Alta - II & Moderada - III & Baixa - IV & Muito Baixa - V \\
\hline A - improvável & & & & & \\
\hline B - extremamente remota & & & & & \\
\hline C - remota & & & & & \\
\hline D - provável & & & & & \\
\hline E - frequente & & & & & \\
\hline
\end{tabular}

FIGURA 6: Matriz para avaliação de riscos.

FONTE: Fireman (2012). 


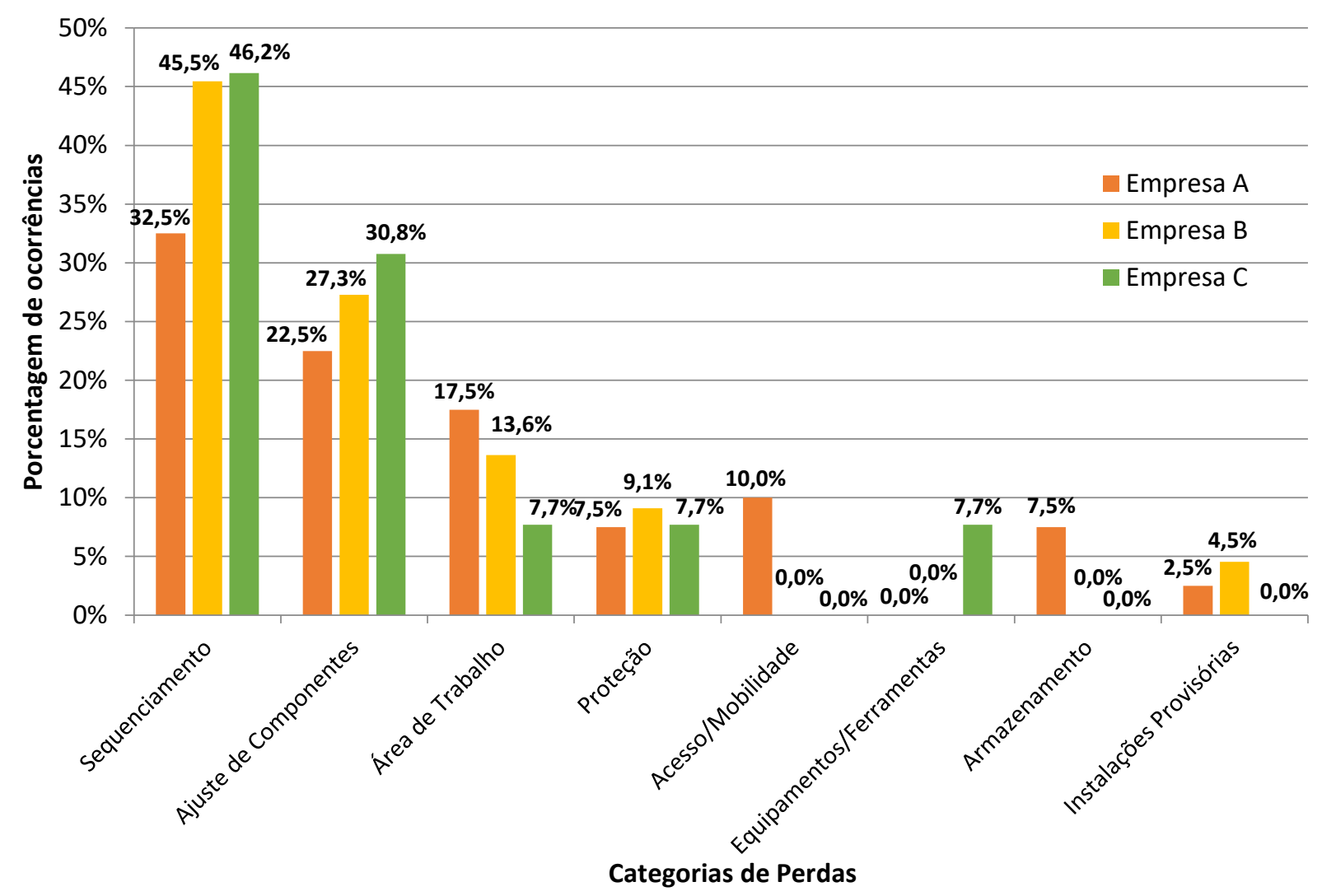

FIGURA 7: Comparativo de categorias de perdas.

FONTE: Autoria própria.

A partir da análise de risco, maior prioridade, de acordo com apresenta-se na Figura 8 a porcentagem de casos classificação da matriz para avaliação de riscos ocorridos para cada categoria identificados com (Figura 6).

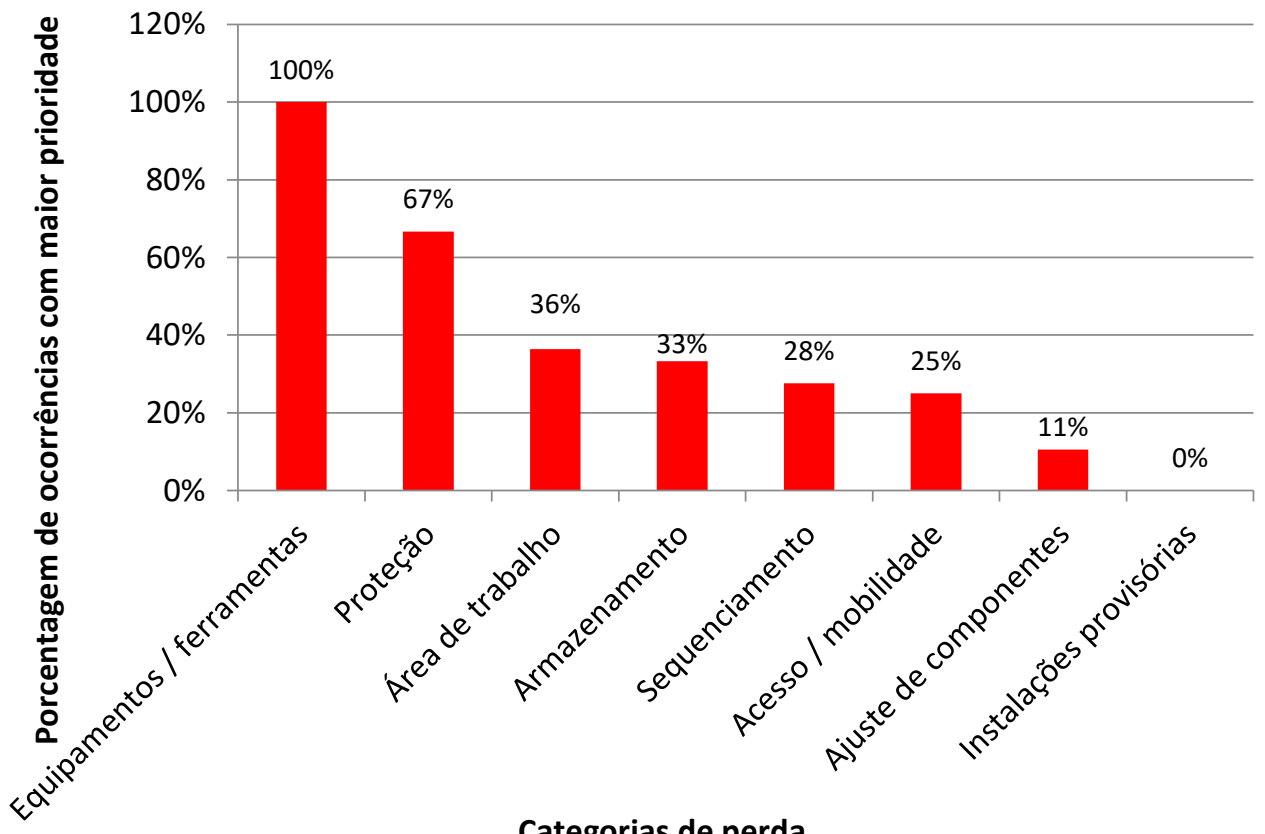

Categorias de perda

FIGURA 8: Porcentagem de casos por categoria com maior prioridade. FONTE: Autoria própria. 
As categorias Acesso/mobilidade e Armazenamento apareceram somente na obra $A$, evidenciando problemas de logística e planejamento de canteiro de obras. Ressalta-se que apenas um desses casos apresentou risco elevado, indicando um caso de maior prioridade (25\%).

A categoria equipamentos/ferramentas apareceu somente na obra $\mathrm{C}, \mathrm{e}, \mathrm{em}$ apenas um caso de rompimento da tubulação de concreto, apesar de ser raro de se ocorrer, deve ser levado em conta, pois pode gerar diversos impactos relevantes. Essa ocorrência evidencia a preocupação dada pelas empresas construtoras quanto ao cumprimento da norma regulamentadora NR 18 Condições e Meio Ambiente de Trabalho na Indústria da Construção, em relação ao uso de equipamentos de segurança individual e coletiva.

É importante ressaltar que no estudo realizado por Sommer (2010), a categoria Proteção aparece diversas vezes com maior índice de ocorrências recorrentes, e com base na Figura 7 observa-se que esta categoria apareceu em quarto lugar, reduzindo este índice. De acordo com o Anuário Estatístico da Previdência Social, no período de 2007 a 2013, ocorreu um aumento significativo no número de acidentes de trabalho. Já na última atualização, de 2014 a 2016, foi observada uma redução na quantidade de acidentes de trabalho na construção civil (AEPS 2016). Segundo Bressan (2016), os riscos elevados levaram ao surgimento de novas profissões na área de saúde e segurança do trabalho, respaldadas por novas legislações e normas regulamentadoras.

De acordo com os dados apresentados, é possível entender a redução da ocorrência de casos relacionados à categoria Proteção nas três empresas estudadas. No entanto, essa categoria ainda deve servir como alerta às empresas, pois segundo a Figura $8,67 \%$ dos casos relacionados à proteção aparecem como maior prioridade, indicando um risco elevado à empresa.

As perdas relacionadas à categoria de sequenciamento ocorreram devido ao atraso na definição dos apartamentos personalizados, falha na verificação de serviços finalizados e falta de acompanhamento durante a execução dos serviços, o que gerava impactos no cronograma, no custo, perda de material e retrabalho.

A Figura 9 exemplifica um caso ocorrido na obra $A$, em que foi necessário retirar o revestimento da cozinha de um apartamento personalizado, em decorrência da modificação e atraso na entrega do projeto personalizado. Destaca-se a ocorrência de atrasos em decorrência da demolição total do apartamento para personalização.

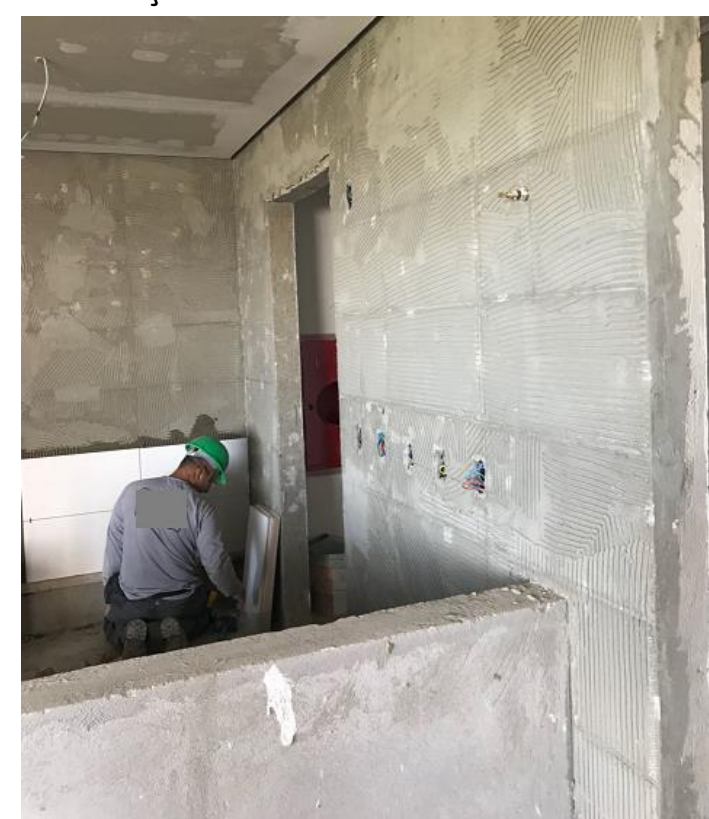

FIGURA 9: Retirada do revestimento da cozinha para adequação do projeto na obra $A$. FONTE: Autoria própria/Obra A.

Além dos casos relacionados às unidades personalizadas, a categoria Sequenciamento apresentou causas ligadas aos serviços interdependentes, principalmente nos serviços de instalações elétricas e hidrossanitárias. A Figura 10 exemplifica um caso em que houve quebra do reboco para colocação exata do registro e pontos de água.

Quanto ao ajuste de componentes, a obra da empresa B precisou aumentar o nível dos degraus da escada devido ao piso da área comum, pois o espelho do primeiro degrau estava desproporcional (Figura 11), ocasionando um ajuste inesperado no serviço. 


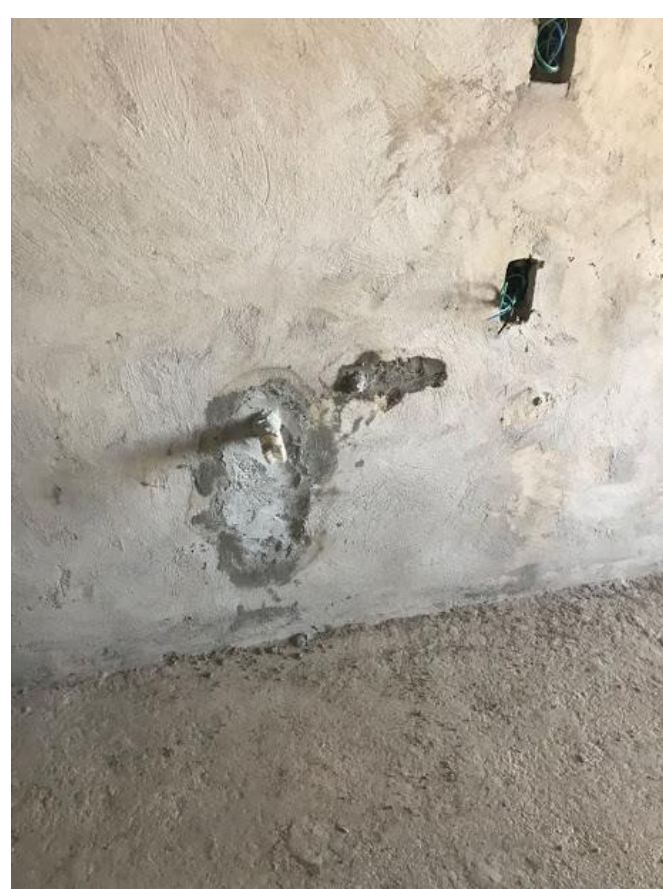

FIGURA 10: Retrabalho nos pontos de água. FONTE: Autoria própria/Obra B.

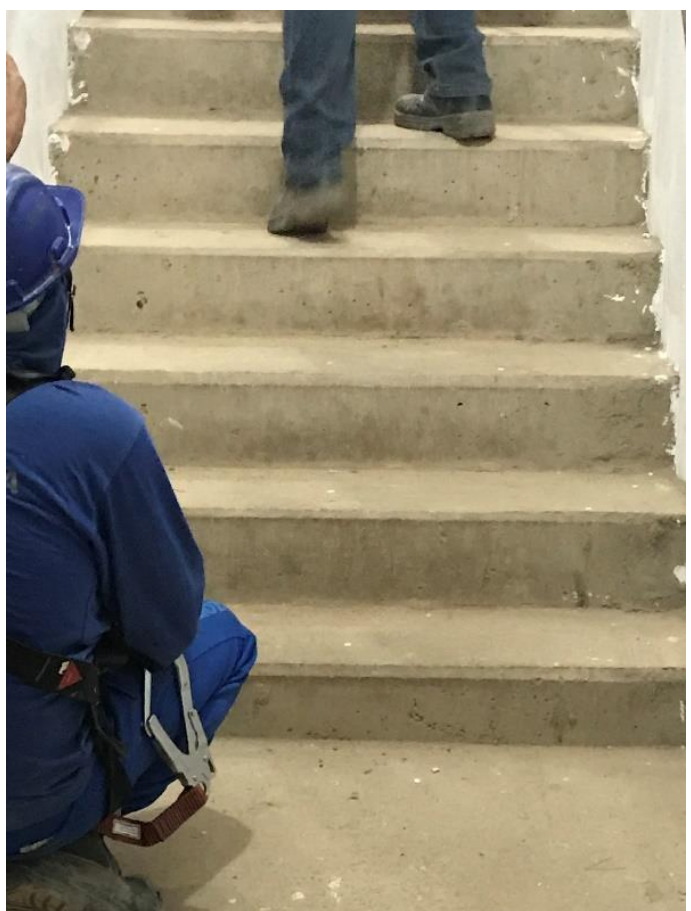

FIGURA 11: Nivelamento da escada na obra B. FONTE: Autoria própria/Obra B.

A Figura 12 apresenta um desplacamento do reboco interno devido à utilização de um componente inadequado para execução do chapisco. Este caso se encaixou em mais de uma categoria, podendo ser analisado como Ajuste de componentes devido ao material inadequado e Sequenciamento, pois o serviço anterior interferiu na tarefa subsequente.

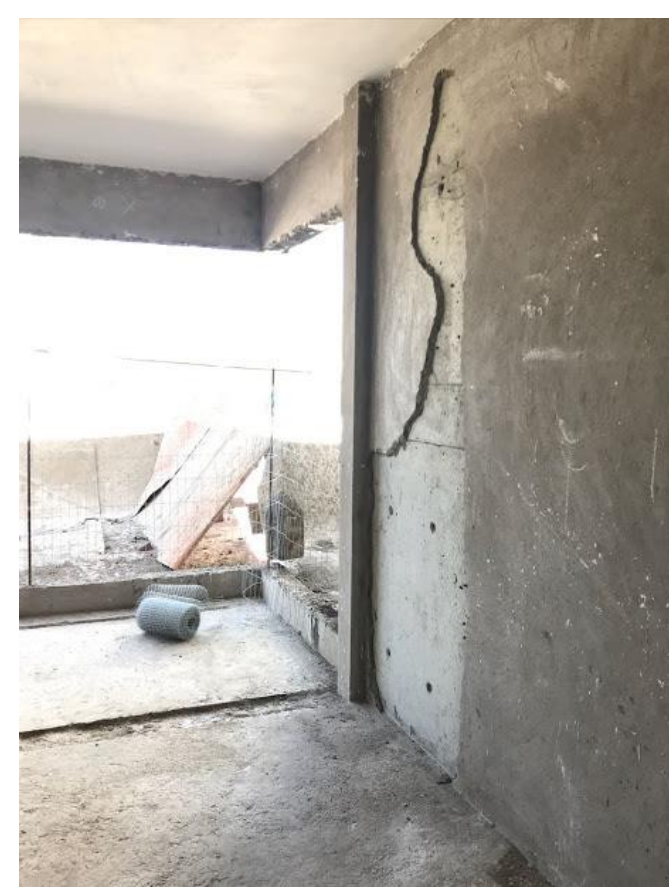

FIGURA 12: Desplacamento do reboco interno na obra B. FONTE: Autoria própria/Obra C.

As perdas referentes à área de trabalho relacionavam-se principalmente a ausência da bancada de apoio adequada para execução do serviço que ocorrem por falha nos treinamentos, negligência por parte dos funcionários, e principalmente falta de fiscalização da construtora para com os terceirizados na disponibilização de materiais de apoio. As Figuras 13 e 14 retratam, respectivamente, casos que ocorreram na obra $B$ e na obra C.

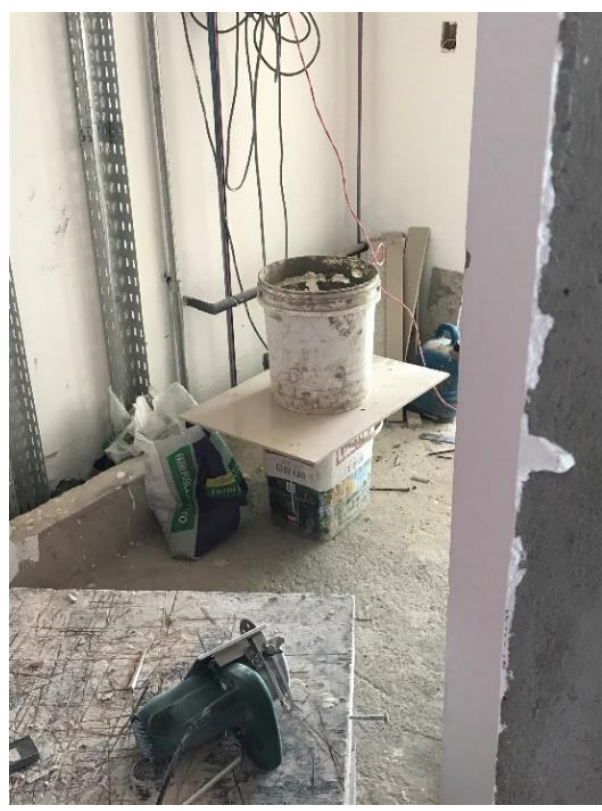

FIGURA 13: Bancada de apoio indevida para execução do serviço na obra $B$.

FONTE: Autoria própria/Obra B. 


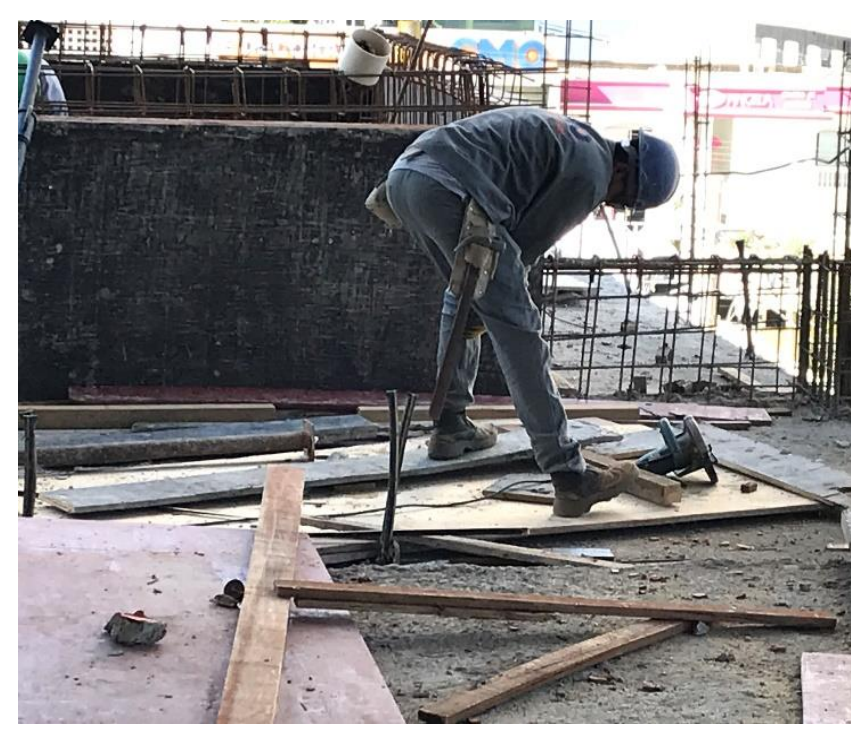

FIGURA 14: Ausência de bancada de apoio para execução do serviço na obra $C$. FONTE: Autoria própria/Obra C.
A Figura 15 apresenta a porcentagem de ocorrência dos pré-requisitos que apresentaram falhas. Destaca-se o item instalações por apresentar a menor ocorrência $(0,9 \%)$ nas obras em estudo.

O pré-requisito informação foi apontado como uma das principais origens das improvisações identificadas como ajuste de componentes, acesso/mobilidade, proteção e sequenciamento nos dados coletados. Em 27,3\% dos casos, relacionavam-se à falta de projetos específicos, incompatibilidade entre projetos e detalhamentos e inexistência de treinamentos específicos dos funcionários.

O item materiais e componentes resultou em $21,8 \%$ das improvisações observadas, as quais ocorreram devido a falhas de logística no momento do recebimento de materiais para realização do serviço ou inadequação quanto ao uso.

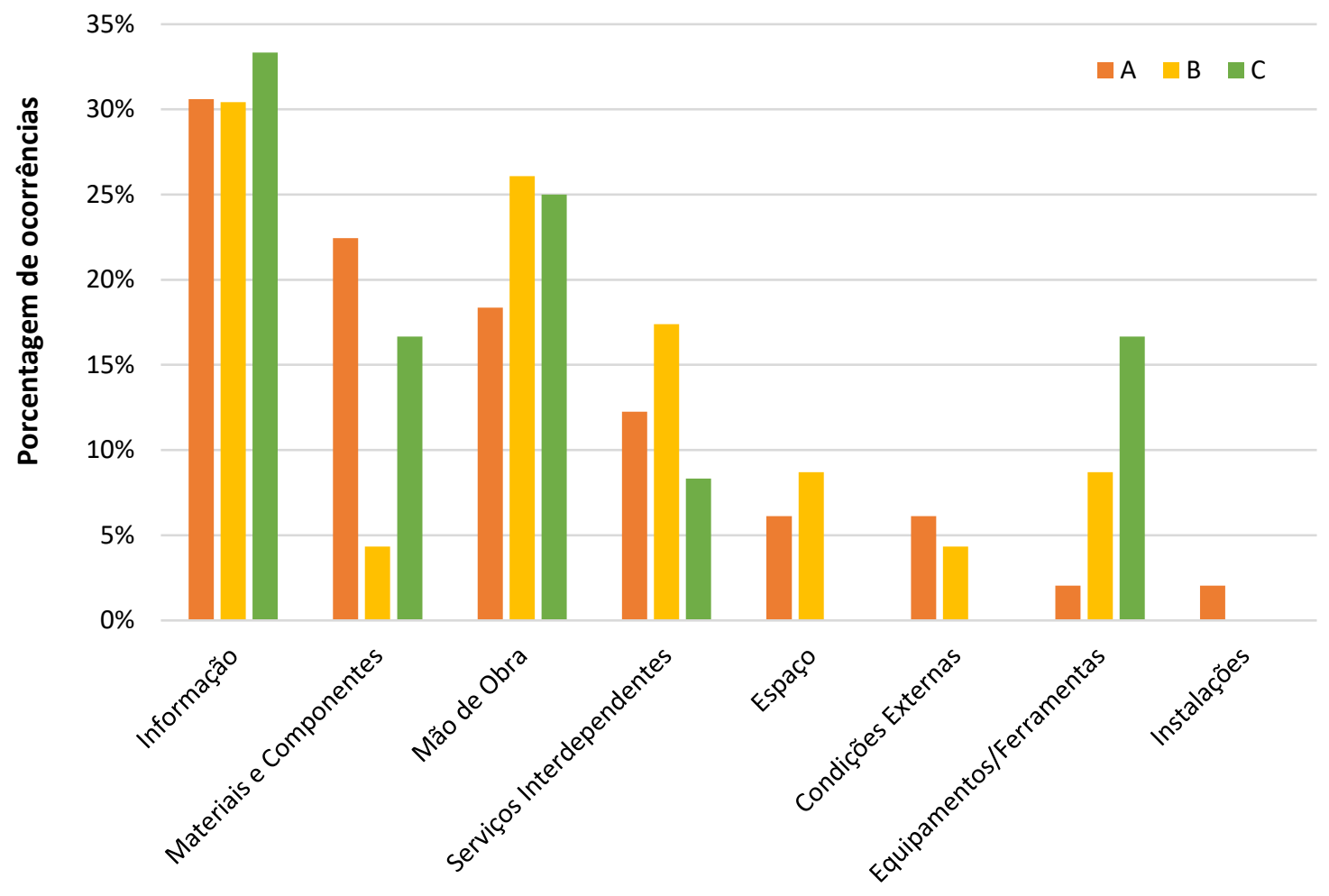

Pré requisitos

FIGURA 15: Porcentagem de ocorrências devido à falha nos pré-requisitos. FONTE: Autoria própria. 
Em relação aos impactos das perdas por improvisação foi observado que $24 \%$ dos casos resultam em retrabalho e, $15 \%$, geram perdas de material, evidenciando assim a relação entre estes dois impactos, conforme apresentado na Figura 16.

A partir do percentual de perdas, das falhas de pré-requisitos e dos possíveis impactos gerados, analisou-se por meio de uma matriz a relação entre os indicadores. É importante ressaltar que cada caso pode apresentar mais de um prérequisito ou impacto, desta forma, resulta em uma soma superior a $100 \%$.

A Figura 17 apresenta a matriz que relaciona o percentual de ocorrência de cada impacto por categoria de perdas.

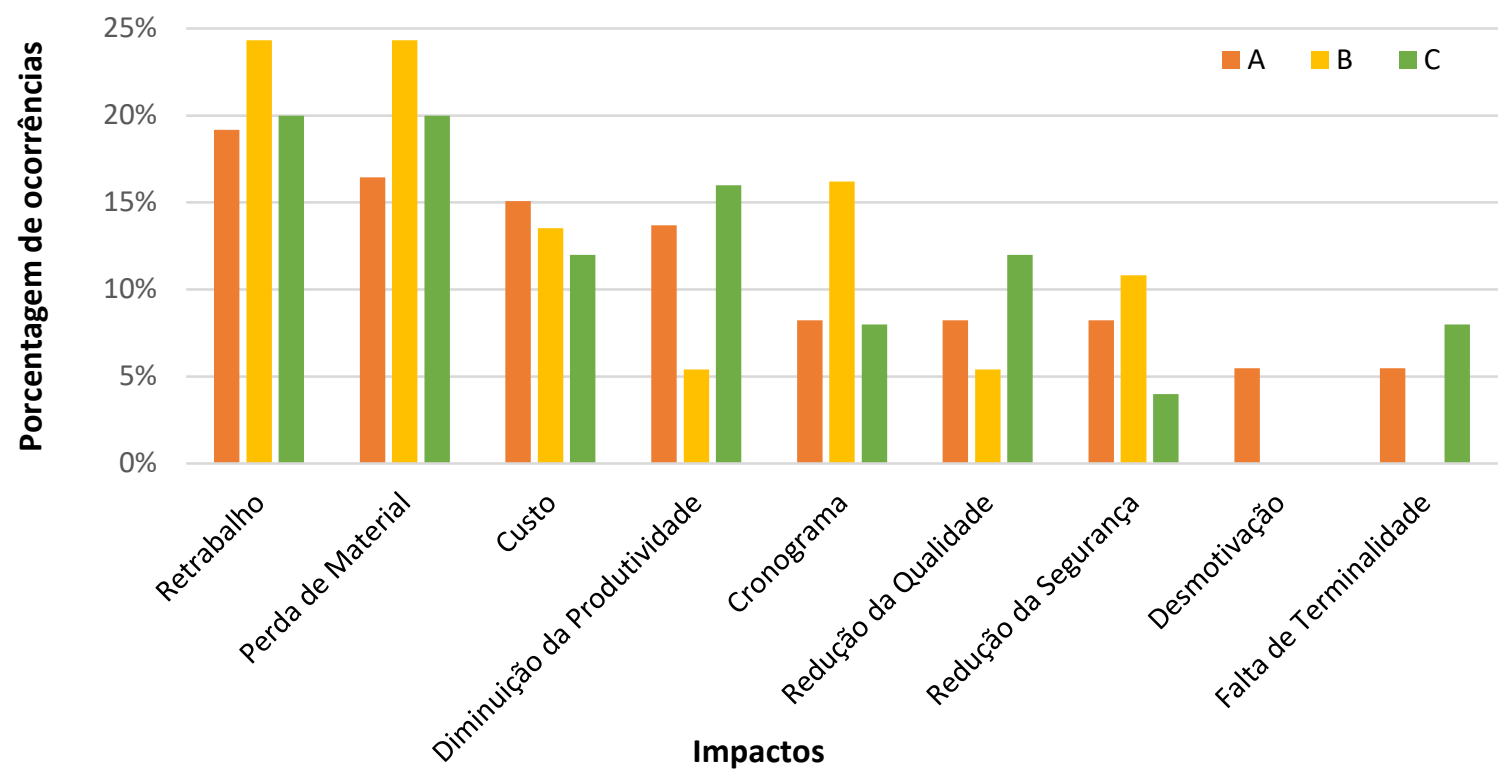

FIGURA 16: Porcentagem de impactos gerados por improvisação.

FONTE: Autoria própria.

\begin{tabular}{|c|c|c|c|c|c|c|c|c|c|}
\hline CATEGORIA X IMPACTO & 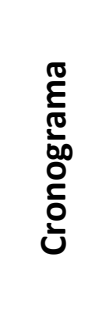 & 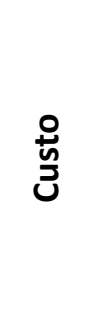 & 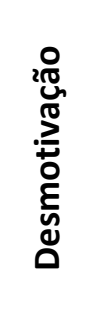 & 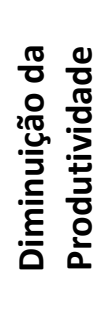 & 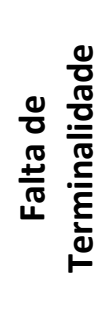 & 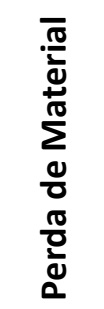 & 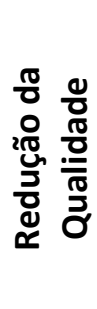 & 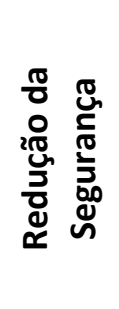 & 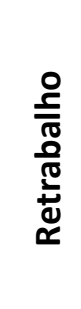 \\
\hline Acesso / mobilidade & $0 \%$ & $0 \%$ & $25 \%$ & $25 \%$ & $0 \%$ & $0 \%$ & $0 \%$ & $75 \%$ & $0 \%$ \\
\hline Ajuste de componentes & $21 \%$ & $37 \%$ & $11 \%$ & $32 \%$ & $11 \%$ & $26 \%$ & $5 \%$ & $0 \%$ & $68 \%$ \\
\hline Área de trabalho & $0 \%$ & $9 \%$ & $9 \%$ & $9 \%$ & $9 \%$ & $9 \%$ & $45 \%$ & $64 \%$ & $36 \%$ \\
\hline Armazenamento & $0 \%$ & $33 \%$ & $33 \%$ & $33 \%$ & $0 \%$ & $67 \%$ & $33 \%$ & $67 \%$ & $0 \%$ \\
\hline $\begin{array}{l}\text { Equipamentos / } \\
\text { ferramentas }\end{array}$ & $0 \%$ & $0 \%$ & $0 \%$ & $0 \%$ & $0 \%$ & $100 \%$ & $0 \%$ & $0 \%$ & $0 \%$ \\
\hline Instalações provisórias & $0 \%$ & $50 \%$ & $50 \%$ & $50 \%$ & $0 \%$ & $0 \%$ & $50 \%$ & $50 \%$ & $0 \%$ \\
\hline Proteção & $0 \%$ & $0 \%$ & $0 \%$ & $0 \%$ & $0 \%$ & $0 \%$ & $33 \%$ & $100 \%$ & $0 \%$ \\
\hline Sequenciamento & $31 \%$ & $38 \%$ & $3 \%$ & $34 \%$ & $17 \%$ & $55 \%$ & $14 \%$ & $0 \%$ & $79 \%$ \\
\hline
\end{tabular}

FIGURA 17: Matriz relação categoria x impacto. FONTE: Autoria própria. 
Observa-se que é grande o número de perdas que podem reduzir a segurança, apesar de não ser o impacto numericamente mais significativo das obras em estudo (11,4\%), tornando-se um ponto de alerta para as empresas, uma vez que o comprometimento da segurança apresenta um risco elevado.

A partir da Figura 18, é possível analisar a relação entre as perdas e sua origem, evidenciando que muitas podem ser as causas para ocorrência de uma determinada perda, levando à improvisações.

A partir das entrevistas realizadas com engenheiros, mestre de obras e encarregados de diversos serviços, foi possível observar, em comum nas três empresas, que nos casos em que ocorria algum impedimento para realização da tarefa, gerando improvisação, o engenheiro responsável receberia a informação somente em casos extremos.

A Figura 19 apresenta a porcentagem de casos analisados de acordo com o índice de prioridade a ser considerado para as empresas. 0 resultado elevado para prioridade intermediária evidencia a discussão anterior.

\begin{tabular}{|c|c|c|c|c|c|c|c|c|}
\hline $\begin{array}{l}\text { CATEGORIA X PRÉ- } \\
\text { REQUISITOS }\end{array}$ & 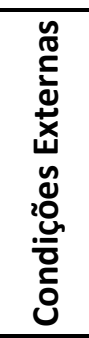 & 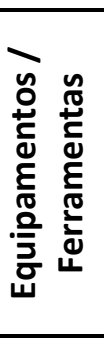 & $\begin{array}{l}\text { ․ } \\
\text { ơ } \\
\text { ơ }\end{array}$ & 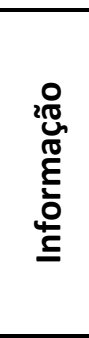 & 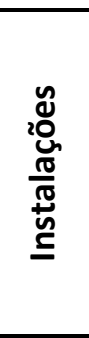 & $\begin{array}{l}\frac{\pi}{0} \\
0 \\
0 \\
010 \\
0 \\
200 \\
\Sigma\end{array}$ & 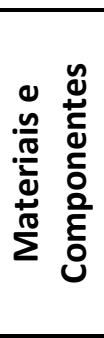 & 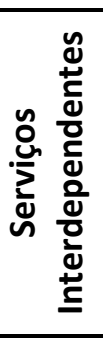 \\
\hline Acesso / mobilidade & $0 \%$ & $0 \%$ & $25 \%$ & $75 \%$ & $0 \%$ & $75 \%$ & $75 \%$ & $0 \%$ \\
\hline Ajuste de componentes & $5 \%$ & $5 \%$ & $0 \%$ & $37 \%$ & $0 \%$ & $26 \%$ & $53 \%$ & $11 \%$ \\
\hline Área de trabalho & $9 \%$ & $27 \%$ & $0 \%$ & $0 \%$ & $0 \%$ & $36 \%$ & $45 \%$ & $27 \%$ \\
\hline Armazenamento & $67 \%$ & $0 \%$ & $100 \%$ & $0 \%$ & $0 \%$ & $0 \%$ & $0 \%$ & $0 \%$ \\
\hline $\begin{array}{l}\text { Equipamentos/ferrament } \\
\text { as }\end{array}$ & $0 \%$ & $100 \%$ & $0 \%$ & $0 \%$ & $0 \%$ & $0 \%$ & $0 \%$ & $0 \%$ \\
\hline Instalações provisórias & $0 \%$ & $0 \%$ & $50 \%$ & $0 \%$ & $50 \%$ & $0 \%$ & $0 \%$ & $0 \%$ \\
\hline Proteção & $17 \%$ & $33 \%$ & $17 \%$ & $50 \%$ & $0 \%$ & $50 \%$ & $50 \%$ & $0 \%$ \\
\hline Sequenciamento & $3 \%$ & $0 \%$ & $0 \%$ & $59 \%$ & $0 \%$ & $28 \%$ & $10 \%$ & $28 \%$ \\
\hline & $\begin{array}{c}70- \\
100 \%\end{array}$ & & $\begin{array}{l}30- \\
69 \%\end{array}$ & & $\begin{array}{c}1- \\
29 \%\end{array}$ & & & \\
\hline
\end{tabular}

FIGURA 18: Matriz relação categoria x pré-requisitos.

FONTE: Autoria própria.

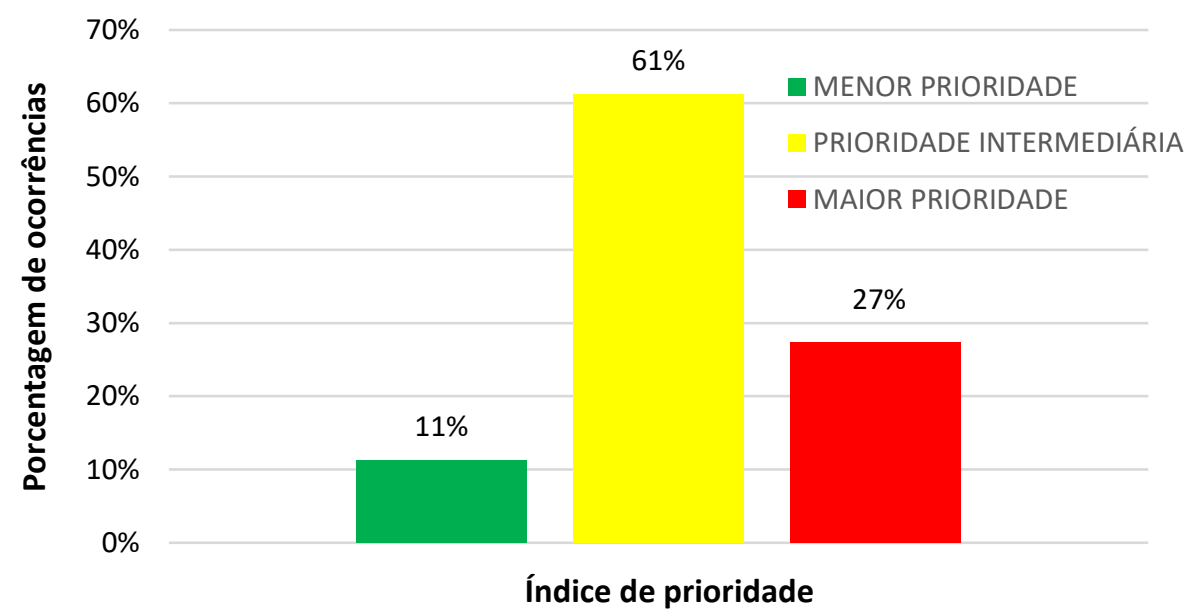

FIGURA 19: Porcentagem de casos ocorridos por índice de prioridade.

FONTE: Autoria própria. 
Diante do exposto, pode-se entender a ocorrência de inúmeros casos prováveis de acontecer, mas que não possuem alta severidade. Contudo, esses seriam casos importantes a serem analisados levando-se em conta a repetitividade de ocorrências que ao final do processo podem gerar problemas maiores e que poderiam ser previstos na etapa de planejamento.

De acordo com os engenheiros responsáveis, as empresas A e B estão em processo de criação de novos métodos para utilização dos dados referentes aos casos descritos em fichas de verificação ou outra plataforma para utilização no planejamento de novos empreendimentos. A empresa C já possui um sistema de gestão da qualidade estruturado, que analisa os casos e os leva em consideração para novos empreendimentos.

$O$ estudo realizado na obra $C$ foi o que obteve menos casos ocorridos de improvisação, esse resultado foi evidenciado pelo fato da empresa possuir um rígido sistema de controle durante o serviço, análise posterior à finalização, e principalmente, oferecer aos colaboradores uma lista de pré-requisitos necessários à execução de cada serviço a ser iniciado na obra e as etapas de construção (Figura 20).

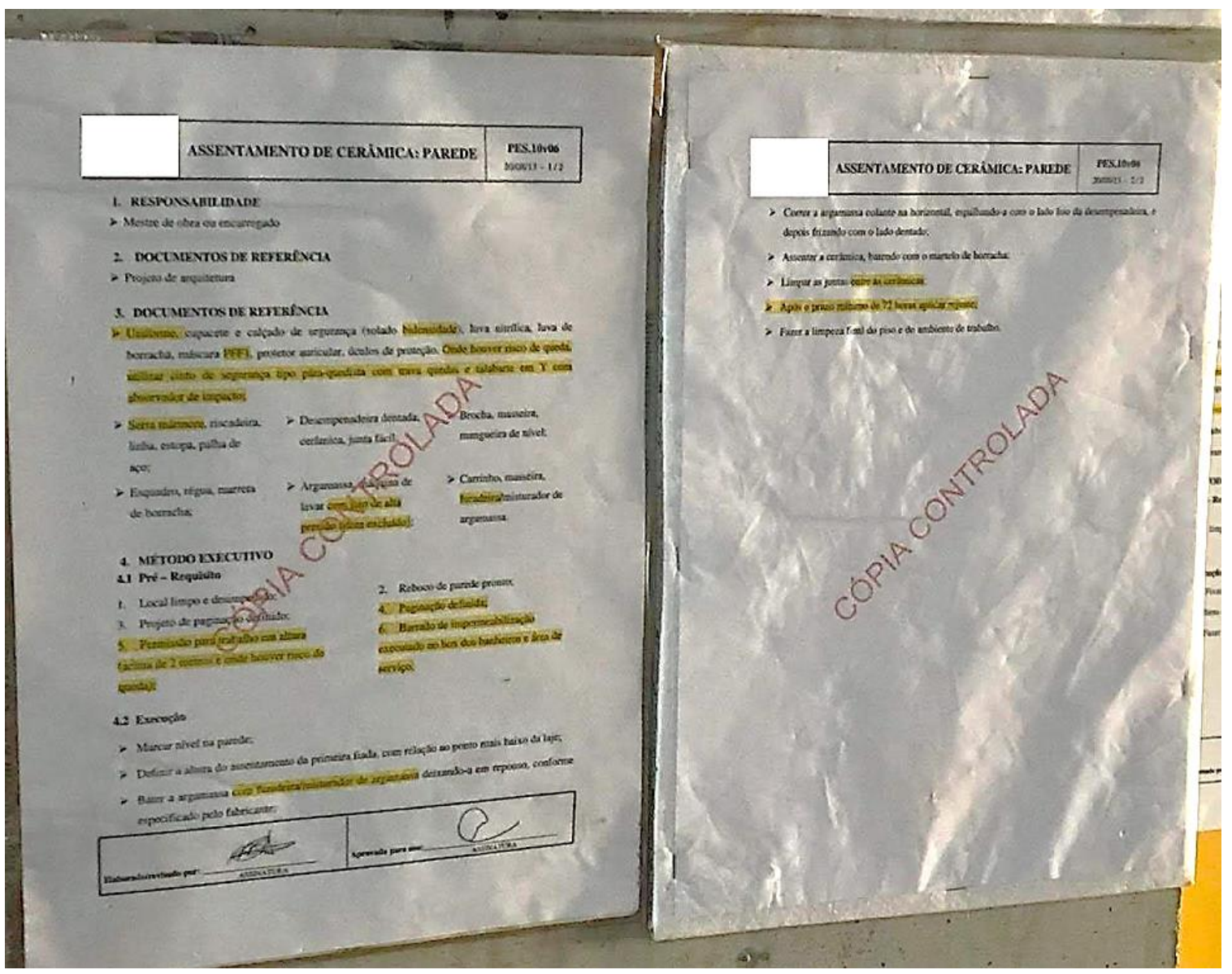

FIGURA 20: Especificações iniciais de serviço. FONTE: Empresa C. 


\section{CONCLUSÕES}

A partir dos resultados obtidos é possível analisar a importância do estudo das perdas relacionadas ao making-do, uma vez que gera outros tipos de perdas, e vai muito além do desperdício de materiais, evidenciando-se questões relacionadas à saúde e segurança da mão de obra e impactos no processo de produção como um todo. Desta forma, além dos impactos propostos em estudos anteriores, as autoras sugeriram o acréscimo de dois novos itens: custo e cronograma.

$O$ sequenciamento e o ajuste de componentes são as categorias mais preocupantes quanto ao planejamento, pois geram inúmeros impactos à produção. Em relação ao sequenciamento, a causa mais significativa observada nas três obras pesquisadas está ligada à personalização dos apartamentos pelos clientes.

A personalização dos imóveis é solicitada pelos clientes finais e viabilizada pela empresa incorporadora, visando atender às necessidades específicas para cada unidade. No entanto, essas alterações geram inúmeros impactos à obra, sendo de extrema importância o cumprimento dos prazos de entregas de projetos por parte do cliente e o controle rígido por parte da empresa, durante a execução dos serviços para que não haja retrabalho, perda de material e falta de terminalidade.

Destaque à segurança, apesar de não ser o impacto mais significativo dos empreendimentos participantes da pesquisa, torna-se um ponto de alerta para as empresas, por possuir um risco elevado.

Vale ressaltar que as situações de registro e particularidades de cada obra influenciam nos dados coletados.

Retrabalho e redução da segurança foram os principais impactos dessa amostra levantada, em concomitância com os resultados obtidos por Sommer (2010), Dinoah, Martins e Ribeiro (2018) e Braga(2018). Destaque para a redução da segurança como sendo o impacto com maior risco e necessidade de intervenções.

Acredita-se que o efetivo controle da execução de planos de ação é uma medida eficaz para a minimização das ocorrências de perdas por making-do.

\section{REFERÊNCIAS BIBLIOGRÁFICAS}

APÓS QUEDA DAS MARGENS DE LUCRO, CONSTRUTORAS DEVEM FOCAR EM PRODUTIVIDADE, APONTA EY. - EY. São Paulo-SP, 2014. Disponível em: $<$ https://www.ey.com/br/pt/services/release_construt oras_devem_focar_em_produtividade>. Acesso em: 8 mar. 2018.

BRAGA, P. B. Análise de perdas por making-do por meio de planilhas dinâmicas. Goiânia, 2018. Trabalho de conclusão de Curso (Graduação em Engenharia Civil), Universidade Federal de Goiás, Goiânia, 2018.

BRANDÃO, C. M., ELIAS, K. V. Identificação de perdas por improvisação em canteiros de obras. Goiânia, 2018. Trabalho de Conclusão de Curso (Graduação em Engenharia Civil), Universidade Federal de Goiás, Goiânia, 2018.

BRESSAN, Brenda. SEGURANÇA DO TRABALHO NA CONSTRUÇÃO CIVIL: SAIBA MAIS SOBRE ESSA ÁREA! Blog Sienge. Florianópolis-SC, 2016. Disponível em $<$ https://www.sienge.com.br/blog/seguranca-dotrabalho-na-construcao-civil/>: Acesso: em 01 de junho de 2018.

FIREMAN, M. C. T. Proposta de método de controle integrado entre produção e qualidade com mensuração de perdas por making-do e pacotes informais. Porto Alegre, 2012. 179 f. Dissertação (Mestrado em Engenharia) - Programa de Pós-Graduação em Engenharia Civil, Universidade Federal do Rio Grande do Sul, Porto Alegre, 2012.

FIREMAN, M. C. T. et al. Integrating Production and Quality Control: monitoring making-do and unfinished work. In: ANNUAL CONFERENCE OF THE INTERNATIONAL GROUP FOR LEAN CONSTRUCTION, 21th, Fortaleza, 2013. Proceedings... Fortaleza, 2013.

FORMOSO, et.al. Perdas na construção civil: conceitos, classificações e seu papel na melhoria do setor, Porto Alegre, p.01-11, 1997. Disponível em: <http://www.pedrasul.com.br/artigos/perdas.pdf > Acesso em 10 out. 2017. 
FORMOSO, C. T. et al. An Exploratory Study on the Measurement and Analysis of Making-Do in Construction Sites. In: ANNUAL CONFERENCE OF THE INTERNATIONAL GROUP FOR LEAN CONSTRUCTION, 19th , Lima, 2011. Proceedings... Lima, 2011.

KOSKELA, L. Application of the New Production Philosophy to Construction. Technical Report no. 72. Center for Integrated Facility Engineering. Stanford University, 1992.

KOSKELA, L. An Exploration Towards a Production Theory and its Application to Construction. Thesis (Ph.D) - Technical Research Centre of Finland, Espoo, 2000.

KOSKELA, L. Making-do - The Eighth Category of Waste. In: CONFERENCE OF THE INTERNATIONAL GROUP FOR LEAN CONSTRUCTION, 12, 2004, Dinamarca. Proceedings...Dinamarca, 2004.

LEÃO, C. F. Proposta de Modelo Para Controle Integrado da Produção e da Qualidade Utilizando Tecnologia de Informação. Porto Alegre, 2014. 179 f. Dissertação (Mestrado em Engenharia) - Programa de PósGraduação em Engenharia Civil, Universidade Federal do Rio Grande do Sul, Porto Alegre, 2014.

OHNO, T., O Sistema Toyota de produção: além da produção em larga escala. Trad. Schumacher C. Porto Alegre: Bookman, 1997.

MARTINS, A. G., DINOAH, L. O., RIBEIRO, R. G. O. S. Determinação das perdas por making-do em empresas goianas. Goiânia, 2018. Trabalho de Conclusão de Curso (Graduação em Engenharia Civil), Universidade Federal de Goiás, Goiânia, 2018.

MINISTÉRIO DA FAZENDA. Anuário Estatístico da Previdência Social. Brasília: 2016.

SANTOS, P. R. R.; SANTOS, D. de G. Investigação de perdas devido ao trabalho inacabado e o seu impacto no tempode ciclo dos processos construtivos. Ambiente Construído, Porto Alegre, v. 17, n. 2, p. 39-52, abr./jun. 2017.

SCARAMUSSA, T. R.; ISATTO, E. L.; FORMOSO, C. T. Análise das causas e da relação causal entre making-do, retrabalho e falta de terminalidade. In: SIMPÓSIO BRASILEIRO DE GESTÃO E ECONOMIA DA CONSTRUÇÃO, 10.. 2017, Fortaleza. Anais, 2017. p. 74.

SOMMER, L. Contribuições para um método de identificação de perdas por improvisação em canteiros de obras. Porto Alegre, 2010. 150 f. Dissertação (Mestrado em Engenharia) - Programa de PósGraduação em Engenharia Civil, Universidade Federal do Rio Grande do Sul, Porto Alegre, 2010. 